\title{
THE LIQUIDITY TRAP, THE REAL BALANCE EFFECT, AND THE FRIEDMAN RULE*
}

\author{
By PETER N. IRELAND ${ }^{1}$ \\ Boston College and National Bureau of Economic Research, U.S.A.
}

\begin{abstract}
This article studies the behavior of the economy and the efficacy of monetary policy under zero nominal interest rates using a model with population growth that nests, as a special case, the conventional specification in which there is a single infinitely lived representative agent. The article shows that with a growing population, monetary policy has distributional consequences that give rise to a real balance effect, thereby eliminating the liquidity trap. These same distributional effects, however, can also work to make many agents much worse off under zero nominal interest rates than they are when the nominal interest rate is positive.
\end{abstract}

\section{OLD IDEAS, NEW MODELS}

Inflation has come full circle. Low before 1960, it rose during the 1960s and peaked during the 1970 s. From this peak, it fell during the 1980 s, finally stabilizing during the 1990s at levels very similar to those prevailing before 1960. This same circular pattern appears in data from virtually all the major industrialized countries - in North America, in Europe, and in Asia-as shown, for example, by Mussa (2000, Table 1, p. 1103).

Monetary economists and central bankers have also come full circle. Concerned mainly with halting and reversing inflation's upward trend during the 1970s and 1980s, analysts and policymakers have more recently rediscovered some of the special problems that can arise under conditions of price stability. These problems received much attention long ago but were ignored for more than a generation. Now they have taken center stage once again.

Chief among these problems are those associated with the liquidity trap, which according to Hicks (1937) lies at the core of Keynes' (1936) economics. Krugman (1998) and Svensson (1999) reconsider the idea of the liquidity trap using state-ofthe-art monetary models in which optimizing agents have rational expectations. In both Krugman's cash-in-advance model and Svensson's money-in-the-utility

\footnotetext{
* Manuscript received June 2003; revised August 2004.

${ }^{1}$ I would like to thank Kevin Moran, Randy Wright, two anonymous referees, participants in the November 2002 meeting of the Canadian Macro Study Group at Queen's University, and participants in seminars at Emory University, the Federal Reserve Board, and the University of Mississippi for very helpful comments and suggestions. This material is based upon work supported by the National Science Foundation under Grant No. SES-0213461. Any opinions, findings, and conclusions or recommendations expressed herein are my own and do not reflect those of the National Bureau of Economic Research or the National Science Foundation. Please address correspondence to: Peter N. Ireland, Boston College, Department of Economics, 140 Commonwealth Avenue, Chestnut Hill, MA 02467-3859, USA; Tel: (617) 552-3687. Fax: (617) 552-2308. E-mail: irelandp@bc.edu.http://www2.bc.edu/irelandp.
} 
function model, households become willing to hoard any additional money that the government chooses to supply after the nominal interest rate reaches its lower bound of zero. The central bank then loses control of the price level and perhaps other key variables as well.

Notably absent from these new models of the liquidity trap, however, is another old idea: that of the real balance effect. First discussed by de Scitovszky (1941), Haberler (1946), and Pigou (1943) and developed most extensively by Patinkin (1965), the real balance effect describes a channel through which a change in real balances, caused either by a change in the nominal money supply or a change in the nominal price level, impacts on household wealth and thereby affects consumption and output. The real balance effect allows the central bank to influence the economy even after the nominal interest rate hits its lower bound. Yet this effect appears nowhere in Krugman and Svensson's analyses. Why?

It has been widely appreciated, since the publication of Barro's (1974) famous article on Ricardian equivalence, that government bonds will not be perceived as a source of private-sector wealth if the households owning those bonds are the same households that must pay all of the taxes that will eventually be used to retire the government's debt. Less widely appreciated, however, is a closely related finding, presented most explicitly by Weil (1991) but also implicit in earlier work by Sachs (1983) and Cohen (1985). These authors show that government-issued fiat money will not be perceived as a source of private-sector wealth if the households owning that money are the same households that, first, receive all of the transfers or pay all of the taxes associated with future changes in the money supply and that, second, incur all of the opportunity costs associated with carrying the money stock between all future periods. In fact, Krugman and Svensson's representative-agent models describe environments in which money is not net wealth. In these models, therefore, the real balance effect disappears.

This article extends Krugman's cash-in-advance framework by introducing growth in the number of infinitely lived households as modeled by Weil. The article shows that with a growing population, households alive in the present pay only a fraction of the taxes levied in the future when the government chooses to contract the money supply. Money becomes net wealth and, consequently, an operative real balance effect gives the central bank control over the price level even when the nominal interest rate equals zero. Only in the special case without population growth - the special case in which the more general model developed here collapses to Krugman's original specification-does the liquidity trap survive.

Introducing population growth in the manner suggested by Weil also serves to resolve a second puzzle that emerges out of Krugman and Svensson's earlier analyses. By associating the case of zero nominal interest rates with the Keynesian liquidity trap, Krugman and Svensson conjure up images of terrible economic outcomes: the Great Depression in the United States or the ongoing lengthy and severe recession in Japan. As emphasized by Cole and Kocherlakota (1998), however, zero nominal interest rates in models such as Krugman and Svensson's are actually associated with highly desirable resource allocations. In fact, zero nominal interest rates in these models are linked more closely to Friedman's (1969) rule for the "Optimum Quantity of Money" than to what Hicks (1937, 
p. 155) calls the "Economics of Depression." But are zero nominal interest rates always good for the economy?

Weiss (1980), Freeman (1985, 1989, 1993), and Smith (2002) all present examples of overlapping generations models in which the Friedman rule fails to maximize private agents' steady-state utility. Bhattacharya et al. (2004) unify and explain these results by tracing them back to distributional effects that are absent in representative-agent models like Krugman and Svensson's. This article also shows that distributional effects - the same distributional effects, as a matter of fact, that give rise to the real balance effect-operate once population growth is introduced into Krugman's cash-in-advance model. Here, these distributional effects can make virtually all households much worse off under zero nominal interest rates than they are when interest rates are positive.

On the other hand, Bhattacharya et al. also demonstrate that in overlapping generations models, the Friedman rule's optimality is typically restored when offsetting fiscal transfers are used to neutralize the distributional effects that deflationary policies would otherwise have. ${ }^{2}$ This result, too, carries over to the model with growth in the number of infinitely lived household studied here. In the end, therefore, this article joins with Bhattacharya et al. by suggesting that the principal dangers posed by deflationary policies have little to do with zero nominal interest rates per se and even less to do with the Keynesian liquidity trap. Rather, both the problems and their ultimate solutions lie in the mechanics through which deflationary policies are implemented.

\section{AN EXTENDED CASH-IN-ADVANCE MODEL}

2.1. Overview. Here, Weil's (1991) continuous-time, money-in-the-utility function model with a growing number of infinitely lived households is recast as a discrete-time, cash-in-advance model. Weil's original specification assigns to each household a utility function that is strictly increasing in two arguments: consumption and real money balances. Since households cannot be satiated by any finite stock of real balances, equilibria in Weil's original model exist only under strictly positive nominal interest rates, ruling out an analysis of the case that Krugman (1998) associates with the liquidity trap. Of course, one could also modify Weil's model in a manner consistent with Svensson (1999) by introducing a satiation point beyond which the marginal utility of real balances equals zero. The cash-inadvance framework used here, however, incorporates the satiation point for real balances in a way that is linked more naturally to the volume of each household's nominal expenditures.

Whitesell (1988) presents a model that is quite similar to Weil's and uses that model to study the effects of money growth on the capital stock and welfare. In fact, both Weil's model and Whitesell's can be viewed as extensions of Blanchard's (1985) model of finite horizons. In Blanchard's model, each agent faces a constant probability of death; meanwhile, newly born agents arrive at a rate that keeps the

\footnotetext{
${ }^{2}$ As noted below, Abel (1987) and Gahvari (1988) present earlier examples of Bhattacharya et al.'s general result.
} 
total population constant. Buiter (1988) generalizes Blanchard's model so as to break the tight link between birth and mortality rates. Buiter's analysis reveals that it is the arrival of newly born agents, rather than the finite horizons of existing agents, that is essential in overturning Barro's (1974) Ricardian equivalence result - a result that, as noted above, relates closely to the presence or absence of monetary wealth effects. Thus, the model used here, like the models used by Weil and Whitesell, retains the essential feature of population growth in an environment where all agents are infinitely lived. And conveniently, this more general model nests, as the special case in which the population growth rate equals zero, the conventional specification that features a single infinitely lived representative agent.

Weil's model, in which goods are received by each household in the form of a constant endowment, is also extended here by allowing each household to produce output with labor. Here, as in Wilson (1979), Cooley and Hansen (1989), Cole and Kocherlakota (1998), and Ireland (2003), positive nominal interest rates distort households' labor supply decisions. Thus, the structure of production and trade gives rise to a mechanism that might make the central bank want to follow the Friedman (1969) rule, which provides for zero nominal interest rates. And, indeed, the Friedman rule is optimal in the special case where the population growth rate equals zero. When the population grows at a positive rate, however, the taxes that the government must levy to implement the Friedman rule generate distributional effects that can make zero nominal interest rates quite costly for many agents.

2.2. Demographic Structure. A new cohort of infinitely lived households is born at the beginning of each period $t=0,1,2, \ldots$ Those households born in a particular period $t=s$ belong to cohort $s$. The arrival of new cohorts causes the total number of households to grow at the constant rate $n \geq 0$. Let $N_{t}$ denote the number of households alive during period $t$. Then given $N_{0}>0$,

$$
N_{t+1}=(1+n) N_{t}
$$

for all $t=0,1,2, \ldots$.

Households of a given cohort are identical, so that it is possible to consider a representative household for each cohort. The representative household of cohort $s$ has preferences described by the utility function

$$
\sum_{t=s}^{\infty} \beta^{t-s} \ln \left[c_{t}^{s}-(1 / \gamma)\left(h_{t}^{s}\right)^{\gamma}\right]
$$

where $1>\beta>0, \gamma>1, c_{t}^{s}$ denotes the household's consumption, and $h_{t}^{s}$ denotes the household's hours worked during period $t$. This specification for utility implies that the marginal rate of substitution between consumption and hours worked depends only on hours worked, so that in particular there are no wealth effects on labor supply. Here, this special assumption greatly simplifies the aggregation 
of quantities chosen by households of different cohorts having different levels of accumulated financial wealth. ${ }^{3}$

Thus, during any given period, the economy consists of many infinitely lived agents of varying ages. As suggested by Weil (1991) and Whitesell (1988), therefore, the population growth rate $n$ serves as a measure of financial disconnectedness and heterogeneity in the economy as a whole. In the special case with $n=0$, however, the model collapses to the more familiar one in which there is a single infinitely lived representative agent.

2.3. Timing of Events. The representative household of cohort $s$ enters each period $t=s, s+1, s+2, \ldots$, with money $M_{t}^{s}$ and bonds $B_{t}^{s}$. Only the initial cohort is endowed with money at birth, and no cohort is endowed with bonds at birth, so that $M_{0}^{0}>0$ but $M_{s}^{s}=0$ for all $s=1,2,3, \ldots$, and $B_{s}^{s}=0$ for all $s=0,1,2, \ldots$ As emphasized by Weil (1991) and Whitesell (1988), these initial conditions formalize the idea that newly born households are not linked financially to previously existing dynasties.

The representative household of each cohort $s$ receives a lump-sum monetary transfer $T_{t}^{s}$ from the central bank at the beginning of each period $t=s, s+1$, $s+2, \ldots$. Also at the beginning of each period, existing bonds mature, providing the representative household of cohort $s$ with $B_{t}^{s}$ additional units of money. The household uses some of its money to purchase $B_{t+1}^{s}$ new bonds at the price of $1 /\left(1+r_{t}\right)$ units of money per bond, where $r_{t}$ denotes the net nominal interest rate between $t$ and $t+1$; the household carries the rest of its money into the goods market.

The description of goods production and trade builds on Lucas' (1980) interpretation of the cash-in-advance model. Each household consists of two members: a shopper and a worker. The shopper from the representative household of cohort $s$ purchases $c_{t}^{s}$ units of output from workers from other households, subject to the cash-in-advance constraint

$$
M_{t}^{s}+T_{t}^{s}+B_{t}^{s}-B_{t+1}^{s} /\left(1+r_{t}\right) \geq P_{t} c_{t}^{s}
$$

where $P_{t}$ denotes the nominal price of goods during period $t$. Meanwhile, the worker from the representative household of cohort $s$ uses $h_{t}^{s}$ units of labor to produce $y_{t}^{s}$ units of output according to the constant-returns-to-scale technology that yields one unit of output for every unit of labor input,

$$
y_{t}^{s}=h_{t}^{s}
$$

The worker sells this output to shoppers from other households for $P_{t} h_{t}^{s}$ units of money. The representative household's two members then reunite to consume the

\footnotetext{
${ }^{3}$ Although this specification for utility is also used by Greenwood et al. (1988), among others, it has sometimes been criticized for being inconsistent with balanced growth in models with rising real wages driven by exogenous technological progress. Along these lines, however, Greenwood et al. (1995) demonstrate that a very similar utility function that does remain consistent with balanced growth emerges from a model with home production when productivity rises at the same average rate across the market and household sectors. For simplicity, however, the model used here abstracts from technological progress all kinds.
} 
shopper's purchases. The household carries $M_{t+1}^{s}$ units of money into period $t+$ 1 ; its choices must satisfy the budget constraint

$$
M_{t}^{s}+T_{t}^{s}+B_{t}^{s}+P_{t} h_{t}^{s} \geq P_{t} c_{t}^{s}+B_{t+1}^{s} /\left(1+r_{t}\right)+M_{t+1}^{s}
$$

In addition to the cash-in-advance and budget constraints (2) and (3), which must hold for all $t=s, s+1, s+2, \ldots$, the representative household's choices must satisfy a set of nonnegativity constraints

$$
h_{t}^{s} \geq 0, \quad M_{t+1}^{s} \geq 0, \quad c_{t}^{s}-(1 / \gamma)\left(h_{t}^{s}\right)^{\gamma}>0
$$

for all $t=s, s+1, s+2, \ldots$. The first two constraints in (4) are standard; the third must be imposed given the special form of the utility function (1).

The representative household of cohort $s$ can borrow by choosing negative values for $B_{t+1}^{s}$ but is not allowed to engage in Ponzi schemes through which it borrows more than it can ever repay. To formalize the constraints that rule out such Ponzi schemes, let $Q_{0}=1$ and

$$
Q_{t}=\prod_{u=0}^{t-1}\left(\frac{1}{1+r_{u}}\right)
$$

for all $t=1,2,3, \ldots$ Then for any $T \geq t \geq 0, Q_{T} / Q_{t}$ measures the present discounted value at the beginning of period $t$ of one unit of money received at the beginning period $T$. The no-Ponzi-scheme constraints are

$$
W_{t+1}^{s}=M_{t+1}^{s}+B_{t+1}^{s}+\sum_{u=t+1}^{\infty}\left(Q_{u} / Q_{t+1}\right)\left(T_{u}^{s}+P_{u} h_{u}^{s}\right) \geq 0
$$

for all $t=s, s+1, s+2, \ldots$ Part 1 of the appendix shows that these no-Ponzischeme constraints imply that the infinite-horizon budget constraint

$$
Q_{t}\left(M_{t}^{s}+B_{t}^{s}\right)+\sum_{u=t}^{\infty} Q_{u}\left(T_{u}^{s}+P_{u} h_{u}^{s}\right) \geq \sum_{u=t}^{\infty} Q_{u}\left[P_{u} c_{u}^{s}+\left(\frac{r_{u}}{1+r_{u}}\right) M_{u+1}^{s}\right]
$$

applies to the household's choices from period $t$ forward. This infinite-horizon budget constraint includes, as sources of funds, the household's beginning-of-period nominal balances $M_{t}^{s}$ as well as the present discounted value of the monetary transfers that the household receives from period $t$ forward. It also includes, as uses of funds, the present discounted value of the opportunity costs that the household incurs when it carries money instead of bonds between all future periods. Ultimately, a comparison between the values of these three items will determine whether or not the real balance effect is operative in general equilibrium.

2.4. Household Optimization. Taking the initial conditions $M_{s}^{s}$ and $B_{s}^{s}$ as given, the representative household of cohort $s$ chooses sequences $\left\{c_{t}^{s}, h_{t}^{s}, M_{t+1}^{s}\right.$, $\left.B_{t+1}^{s}\right\}_{t=s}^{\infty}$ to maximize the utility function (1) subject to the constraints (2)-(5), 
each of which must hold for all $t=s, s+1, s+2, \ldots$ Equivalently, (3) and (5) can be replaced by (6) in this statement of the household's problem.

Define the real variables

$$
m_{t}^{s}=M_{t}^{s} / P_{t}, \quad b_{t}^{s}=B_{t}^{s} / P_{t}, \quad \tau_{t}^{s}=T_{t}^{s} / P_{t}
$$

and let $\pi_{t}$ denote the net inflation rate between $t-1$ and $t$

$$
1+\pi_{t}=P_{t} / P_{t-1}
$$

In addition, let

$$
1+x_{t}=\left(1+r_{t}\right) /\left(1+\pi_{t+1}\right)
$$

define the net real interest rate $x_{t}$ during period $t$, and let

$$
a_{t}^{s}=m_{t}^{s}+b_{t}^{s}
$$

summarize the representative household's real asset position at the beginning of period $t$. Part A.2 of the appendix demonstrates that in terms of these newly defined variables, the conditions

$$
h_{t}^{s}=\left(\frac{1}{1+r_{t}}\right)^{1 /(\gamma-1)}
$$

$$
\left(1+\pi_{t+1}\right) m_{t+1}^{s} \geq h_{t}^{s}, \quad r_{t} \geq 0, \quad r_{t}\left[\left(1+\pi_{t+1}\right) m_{t+1}^{s}-h_{t}^{s}\right]=0
$$

$$
\begin{aligned}
c_{t}^{s}= & \frac{1}{\gamma}\left(\frac{1}{1+r_{t}}\right)^{\gamma /(\gamma-1)} \\
& +(1-\beta)\left\{a_{t}^{s}+\sum_{u=t}^{\infty}\left[\prod_{v=t}^{u-1}\left(\frac{1}{1+x_{v}}\right)\right]\left[\tau_{u}^{s}+\left(\frac{\gamma-1}{\gamma}\right)\left(\frac{1}{1+r_{u}}\right)^{\gamma /(\gamma-1)}\right]\right\}
\end{aligned}
$$

and

$$
a_{t+1}^{s}=\left(1+x_{t}\right)\left[a_{t}^{s}+\tau_{t}^{s}+\left(\frac{1}{1+r_{t}}\right)^{\gamma /(\gamma-1)}-c_{t}^{s}\right]
$$

for all $t=s, s+1, s+2, \ldots$, and

$$
\lim _{t \rightarrow \infty}\left[\prod_{v=s}^{t}\left(\frac{1}{1+x_{v}}\right)\right] a_{t+1}^{s}=0
$$

are both necessary and sufficient for a solution to the household's problem. 
Equation (9) confirms that positive nominal interest rates distort the household's labor supply decisions, as discussed by Wilson (1979), Cooley and Hansen (1989), Cole and Kocherlakota (1998), and Ireland (2003). Equation (10) restates the cash-in-advance constraint. It reveals that when the nominal interest rate hits its lower bound of zero, the cash-in-advance constraint no longer binds; this is the case that Krugman (1998) associates with the liquidity trap.

Equation (11) defines the household's consumption function, which according to the permanent income hypothesis links consumption to total wealth. Embedded into the right-hand side of (11) are the same three components of monetary wealth identified in (6): the household's current money balances, the present discounted value of the future monetary transfers, and the present discounted value of the opportunity costs associated with carrying money instead of bonds between future periods. Once again, a comparison between the values of these three items will determine whether or not the real balance effect appears in equilibrium.

Equation (12) governs the evolution of the household's financial wealth. It shows that the household accumulates wealth as it earns interest on its existing assets and as it receives monetary transfers from the government; the household also accumulates wealth by working more and consuming less. Finally, (13) is the household's transversality condition. If the limit on the left-hand side of (13) was negative, then the household would be violating the no-Ponzi-scheme constraints in (5); if, on the other hand, the limit was positive, then the household could achieve a preferred consumption profile, without violating any of its constraints, by drawing down its stock of financial assets.

2.5. Aggregation. Define aggregate per household financial wealth during period $t$ as

$$
a_{t}=\frac{N_{0} a_{t}^{0}+\sum_{s=1}^{t}\left(N_{s}-N_{s-1}\right) a_{t}^{s}}{N_{t}}
$$

and define aggregate per household real money balances $m_{t}$, real bond holdings $b_{t}$, hours worked $h_{t}$, and consumption $c_{t}$ similarly. Also, and importantly, let

$$
\tau_{t}=\frac{N_{0} \tau_{t}^{0}+\sum_{s=1}^{t}\left(N_{s}-N_{s-1}\right) \tau_{t}^{s}}{N_{t}}
$$

denote aggregate per household real money transfers made to all agents alive during period $t$ and let

$$
\tau_{u, t}=\frac{N_{0} \tau_{u}^{0}+\sum_{s=1}^{t}\left(N_{s}-N_{s-1}\right) \tau_{u}^{s}}{N_{t}}
$$

denote aggregate per household real monetary transfers made during period $u \geq t$ to those households that were alive during period $t$. Then, of course, $\tau_{t, t}=$ $\tau_{t}$ for all $t=0,1,2, \ldots$ But for $u=t+1, t+2, t+3, \ldots, \tau_{u, t}$ will generally differ 
from $\tau_{u}$, since some of the monetary transfers made during period $u$ may go to households born during periods $t+1$ through $u$.

In terms of these aggregates, (8)-(12) become

$$
a_{t}=m_{t}+b_{t}
$$

$$
h_{t}=\left(\frac{1}{1+r_{t}}\right)^{1 /(\gamma-1)}
$$

$$
(1+n)\left(1+\pi_{t+1}\right) m_{t+1} \geq h_{t}, r_{t} \geq 0, r_{t}\left[(1+n)\left(1+\pi_{t+1}\right) m_{t+1}-h_{t}\right]=0
$$

$$
\begin{aligned}
c_{t}= & \frac{1}{\gamma}\left(\frac{1}{1+r_{t}}\right)^{\gamma /(\gamma-1)} \\
& +(1-\beta)\left\{a_{t}+\sum_{u=t}^{\infty}\left[\prod_{v=t}^{u-1}\left(\frac{1}{1+x_{v}}\right)\right]\left[\tau_{u, t}+\left(\frac{\gamma-1}{\gamma}\right)\left(\frac{1}{1+r_{u}}\right)^{\gamma /(\gamma-1)}\right]\right\}
\end{aligned}
$$

and

$$
a_{t+1}=\left(\frac{1+x_{t}}{1+n}\right)\left[a_{t}+\tau_{t}+\left(\frac{1}{1+r_{t}}\right)^{\gamma /(\gamma-1)}-c_{t}\right]
$$

for all $t=0,1,2, \ldots$ Although (14) -(16) are straightforward analogs to (8)-(10), a comparison of (17) to (11) reveals that aggregate per household consumption during period $t$ depends on the real value of future monetary transfers, but only to the extent that those transfers will be made to households that are alive during period $t$. Similarly, a comparison of (18) to (12) suggests that aggregate per household financial wealth tends to grow at a slower rate than each individual household's financial wealth, since newly born households start their lives without money and bonds.

2.6. Equilibrium Conditions. Equations (7) and (14)-(18) form a system of six equations in the 10 aggregate variables $x_{t}, r_{t}, \pi_{t+1}, a_{t}, m_{t}, b_{t}, h_{t}, c_{t}, \tau_{t}$, and $\tau_{u, t}$. This system can be closed by imposing the market-clearing conditions for goods and labor,

$$
h_{t}=c_{t}
$$

for all $t=0,1,2, \ldots$, and by making assumptions about the government's supply of money and bonds. 
Accordingly, suppose first that the government issues no bonds. Then, in equilibrium,

$$
b_{t}=0
$$

must also hold for all $t=0,1,2, \ldots$ Note that (20) only requires that aggregate per household bonds equal zero; it does not rule out the possibility that for any individual household, $b_{t}^{s}$ will be nonzero as households of different cohorts borrow and lend among themselves by trading bonds.

Suppose next that the government acts to expand the total nominal money supply at the constant rate $\sigma$ by making equal lump-sum transfers to all households alive during each period. Then, in equilibrium,

$$
\tau_{t}=\sigma m_{t}
$$

and

$$
\tau_{u, t}=\sigma m_{u}
$$

will hold for all $t=0,1,2, \ldots$, and $u=t, t+1, t+2, \ldots$.

Under government policies described by (20)-(22), (14) immediately implies that

$$
a_{t}=m_{t}
$$

whereas (7) and (15)-(18) become

$$
(1+n)\left(1+\pi_{t+1}\right) m_{t+1} \geq c_{t}, r_{t} \geq 0, r_{t}\left[(1+n)\left(1+\pi_{t+1}\right) m_{t+1}-c_{t}\right]=0
$$

$$
\begin{aligned}
c_{t}= & \frac{1}{\gamma}\left(\frac{1}{1+r_{t}}\right)^{\gamma /(\gamma-1)} \\
& +(1-\beta)\left\{m_{t}+\sum_{u=t}^{\infty}\left[\prod_{v=t}^{u-1}\left(\frac{1}{1+x_{v}}\right)\right]\left[\sigma m_{u}+\left(\frac{\gamma-1}{\gamma}\right)\left(\frac{1}{1+r_{u}}\right)^{\gamma /(\gamma-1)}\right]\right\}
\end{aligned}
$$

and

$$
m_{t+1}=\left(\frac{1+x_{t}}{1+n}\right)\left[(1+\sigma) m_{t}+\left(\frac{1}{1+r_{t}}\right)^{\gamma /(\gamma-1)}-c_{t}\right]
$$


for all $t=0,1,2, \ldots$ Given the government's choice of the money growth rate $\sigma,(24)-(28)$ determine the equilibrium behavior of the five aggregate variables $x_{t}, r_{t}, \pi_{t+1}, m_{t}$, and $c_{t}$; paths for the remaining five aggregates $a_{t}, b_{t}, h_{t}, \tau_{t}$, and $\tau_{u, t}$ then follow immediately from (19)-(23).

2.7. Steady-State Equilibria. Equations (24)-(28) imply that under a policy of constant money growth $\sigma$ via equal lump-sum transfers, a steady-state equilibrium exists in which aggregate variables are constant over time, with $x_{t}=x, r_{t}=r, \pi_{t+1}=$ $\pi, m_{t}=m$, and $c_{t}=c$ for all $t=0,1,2, \ldots{ }^{4}$ Part A.3 of the appendix demonstrates that, more specifically, (24)-(28) require the five steady-state values $x, r, \pi, m$, and $c$ to satisfy

$$
\begin{gathered}
1+x=(1+r) /(1+\pi) \\
1+\pi=(1+\sigma) /(1+n) \\
c=\left(\frac{1}{1+r}\right)^{1 /(\gamma-1)} \\
(1+\sigma) m \geq c, \quad r \geq 0, \quad r[(1+\sigma) m-c]=0
\end{gathered}
$$

and

$$
\begin{aligned}
c= & \frac{1}{\gamma}\left(\frac{1}{1+r}\right)^{\gamma /(\gamma-1)} \\
& +(1-\beta)\left\{\left[1+\left(\frac{1+x}{x}\right) \sigma\right] m+\left(\frac{\gamma-1}{\gamma}\right)\left(\frac{1+x}{x}\right)\left(\frac{1}{1+r}\right)^{\gamma /(\gamma-1)}\right\}
\end{aligned}
$$

Equation (29) defines the steady-state real interest rate as the difference between the nominal interest rate and the inflation rate; similarly, (30) determines the steady-state inflation rate as the difference between the money growth rate and the population growth rate. Equation (31) confirms that across steady-state equilibria, higher nominal interest rates reduce consumption and output as well as employment. Equation (32), derived from the cash-in-advance constraint, describes the aggregate demand for money, and (33) is the aggregate consumption function with the steady-state conditions imposed.

\footnotetext{
${ }^{4}$ In addition, (24)-(28) characterize the model's dynamics away from the steady state. As noted below, however, this model has no predetermined state variables: Hence, if a steady state exists, a perfect foresight equilibrium also exists in which the economy begins and remains forever in that steady state. A more thorough analysis of the model's dynamics would therefore serve only to confirm or rule out the existence of multiple perfect foresight equilibria of the kind studied in a more conventional cash-in-advance specification by Woodford (1994).
} 


\section{THE LIQUIDITY TRAP AND THE REAL BALANCE EFFECT}

What do the steady-state conditions (29)-(33) imply about the behavior of the economy and the efficacy of monetary policy under zero nominal interest rates? To answer this question, it is helpful to consider two cases. The first case sets $n=0$, so that there is no population growth. This first case is therefore the special case in which the more general model developed here reduces to the familiar specification, used by Krugman (1998) and many others, in which there is a single representative agent. And, indeed, Krugman's liquidity trap appears in this special case: The central bank loses control over the price level when the nominal interest rate hits its lower bound of zero. In the second case with $n>0$, however, a real balance effect emerges, enabling the central bank to control the price level even under a zero nominal interest rate.

3.1. The Liquidity Trap. When $r=0$ and $n=0$, so that both the nominal interest rate and the population growth rate equal zero, (29)-(31) and (33) imply that

$$
\begin{aligned}
& 1+\sigma=1+\pi=\beta \\
& 1+x=1 / \beta
\end{aligned}
$$

and

$$
c=1
$$

In this steady state, the central bank follows the Friedman (1969) rule, contracting the money stock at the rate of time preference and generating a rate of deflation that is consistent with the zero nominal interest rate. As in Sidrauski's (1967) famous model, the steady-state real interest rate is pinned down by the rate of time preference, and as discussed below, consumption, output, and employment are at their Pareto optimal levels.

But while (34)-(36) provide unique solutions for $\pi, x$, and $c$, the cash-in-advance constraint (32) requires only that

$$
m \geq 1 / \beta
$$

Since $r=0$, the opportunity cost of holding money instead of bonds is zero. Households are therefore willing to hoard arbitrarily large stocks of real money balances. A continuum of steady-state equilibria exists, each corresponding to a value of $m$ that satisfies (37).

Thus, in this case without population growth, the model exhibits what McCallum (1986, p. 137) refers to as solution "multiplicity," as opposed to the less severe problem of price-level "indeterminacy." Multiple values of the real balance variable $m$ satisfy (37). Hence, even if the central bank chooses an initial value $M_{0}^{0}$ for the level of the nominal money supply in addition to the constant money growth rate 
$\sigma$, there are still many distinct time paths for the price level that are consistent with all of the steady-state conditions.

One can, therefore, follow Krugman (1998) by associating this case with the Keynesian liquidity trap. Here, variations in the government's choice of $M_{0}^{0}$, holding the money growth rate $\sigma$ fixed, need not be associated with movements in the price level. With nominal interest rates frozen at their lower bound of zero, the central bank loses the ability to influence the behavior of prices.

3.2. The Real Balance Effect. When $r=0$ but $n>0$, the nominal interest rate continues to equal zero but the population grows at a positive rate. Equations (29)-(31) and (33) imply that

$$
\begin{aligned}
1+\pi & =(1+\sigma) /(1+n) \\
1+x & =(1+n) /(1+\sigma) \\
c & =1
\end{aligned}
$$

and

$$
m=\frac{(\gamma-1)[\beta(1+n)-(1+\sigma)]}{\gamma(1-\beta)(1+\sigma) n}
$$

while (32) requires that the money growth rate satisfy

$$
\beta(1+n)-n(1-\beta)\left(\frac{\gamma}{\gamma-1}\right) \geq 1+\sigma
$$

There is, in addition to (42), a second condition that places restrictions on the money growth rate when $n>0$ : the condition $c_{t}^{s}-(1 / \gamma)\left(h_{t}^{s}\right)^{\gamma}>0$ from the set of nonnegativity constraints in (4). Part A.4 of the appendix shows that in a steady state, this additional condition holds if and only if

$$
1+\sigma>\beta
$$

Intuitively, (42) requires the money growth rate to be low enough to be consistent with a zero nominal interest rate, whereas (43) guarantees that the lump-sum taxes required to implement a policy of zero nominal interest rates do not become so large that newly born households cannot afford to pay them and still consume. So long as $\beta$ is sufficiently close to 1 or, more precisely, so long as $\beta>\gamma /(2 \gamma-1)$, the upper bound in (42) exceeds the lower bound in (43), and there is a range of values for $\sigma$ that satisfy both constraints. ${ }^{5}$

\footnotetext{
${ }^{5}$ When, for instance, $\gamma=1.6$ as in the numerical examples presented below, a range of values for $\sigma$ satisfying both (42) and (43) exists for all values of $\beta$ exceeding 0.7273 .
} 
Equation (39) reveals that in this case with population growth, the steady-state real interest rate is no longer tied to the rate of time preference; instead, a Tobin (1965) effect arises through which the real interest rate falls when the money growth rate rises. This Tobin effect also appears under positive nominal interest rates, as discussed by Weil (1991) and, more extensively, Whitesell (1988). Here, in fact, the presence of the Tobin effect explains why equilibria with zero nominal interest rates exist over the entire range of money growth rates $\sigma$ satisfying (42) and (43): Across these equilibria, a decrease in inflation brought about by a decrease in the money growth rate is accompanied by an offsetting rise in the real interest rate, leaving the nominal interest rate constant at zero. Note from (41), however, that each of these equilibria with zero nominal interest rates features a different level of aggregate per household real money balances; moreover, as shown below, patterns of consumption and asset ownership for each individual household differ greatly across these zero interest rate equilibria.

For any given rate of money growth satisfying (42) and (43), however, (41) serves to uniquely determine the level of steady-state real balances. Thus, by selecting the initial value $M_{0}^{0}$ for the level of the nominal money supply as well as the money growth rate $\sigma$, the central bank can, through its choice of policy, determine a unique path for the nominal price level. This result - that when $n>$ $0, m$ is uniquely determined, even when $r=0$ - cannot be found in Weil (1991) or Whitesell (1988), since their money-in-the-utility function specifications require the nominal interest rate to be positive. But why does Krugman's (1998) liquidity trap vanish when $n$ becomes positive?

Sachs (1983), Cohen (1985), and Weil (1991) identify the three components of the private sector's monetary wealth that appear explicitly in the infinite-horizon budget constraint (6) and implicitly in the consumption functions (11), (17), (27), and (33). First, there is the value of the current period's money supply. Second, there is the present discounted value of all future transfers or taxes that households alive today will receive or pay as the government expands or contracts the money supply over time. Third, there is the present discounted value of the opportunity costs that households alive today will incur as they carry money instead of bonds between all future periods. When the nominal interest rate equals zero, only the first two of these three components remain, so that aggregate per household real monetary wealth during period $t$ is measured by

$$
\Omega_{t}=m_{t}+\sum_{u=t}^{\infty}\left[\prod_{v=t}^{u-1}\left(\frac{1}{1+x_{v}}\right)\right] \tau_{u, t}
$$

In a steady state with constant money growth via equal lump-sum transfers, (22) implies that $\Omega_{t}$ is constant and equal to

$$
\Omega=\left[1+\left(\frac{1+x}{x}\right) \sigma\right] m
$$

In general, this measure of monetary wealth enters into the aggregate consumption function (33). In the special case with $n=0$ and $r=0$, however, (34), (35), and (44) imply that 


$$
\Omega=\left[1+\left(\frac{1}{1-\beta}\right)(\beta-1)\right] m=0
$$

Without population growth, the households owning the current period's money stock are exactly the same households that pay all of the taxes required to implement a policy of zero nominal interest rates. Thus, as noted by Weil, an argument analogous to the one underlying Barro's (1974) Ricardian equivalence theorem implies that government-issued money, like government-issued bonds, will not be a source of private net wealth.

When $n>0$, on the other hand, (39) and (44) imply that

$$
\Omega=n\left(\frac{1+\sigma}{n-\sigma}\right) m>0
$$

In this case, households alive during any period $t$ pay only a fraction of the future taxes required to keep the nominal interest rate at zero; households born in later periods share the total tax burden. Hence, money is a component of private net wealth. Since real balances enter nontrivially into the aggregate consumption function (33), $m$ is uniquely determined, even when the cash-in-advance constraint (32) does not bind. The central bank retains control over the price level, even when the nominal interest rate is zero.

de Scitovszky (1941), Haberler (1946), Pigou (1943), and Patinkin (1965) describe the real balance effect. According to these authors, real money balances form a component of private sector wealth and therefore enter into the aggregate consumption function. As a result, a change in the level of real balances, brought about either by a change in the nominal money supply or a change in the nominal price level, gives rise to changes in consumption and output. Thus, the real balance effect allows the central bank to influence the economy even after the nominal interest rate reaches its lower bound. Here, the real balance effect operates in exactly this way, so long as the population grows at a positive rate. Only in the special case without population growth, where money is not net wealth, does the liquidity trap survive.

\section{THE WELFARE COSTS OF DEFLATION}

The results from above resolve one of the puzzles left over from Krugman (1998) and Svensson's (1999) analyses of the liquidity trap. These results show that a real balance effect of the kind described by de Scitovszky (1941), Haberler (1946), Pigou (1943), and Patinkin (1965) fails to appear in Krugman and Svensson's models because these models, which feature a single infinitely lived representative agent, depict economic environments in which government-issued money is not a component of aggregate private sector wealth. When population growth is introduced into one of these models, in the manner suggested by Weil (1991) and Whitesell (1988), money becomes net wealth. The real balance effect reappears, and the central bank regains control over the price level even when the nominal interest rate equals zero. The real balance effect reappears because monetary 
policies have distributional consequences: The households owning money today pay only some of the taxes or receive some of the transfers associated with future changes in the money supply.

The same distributional consequences help resolve a second puzzle emerging from Krugman and Svensson's analyses. By associating the case of zero nominal interest rates with the Keynesian liquidity trap, Krugman and Svensson conjure up images of economic depression. But, in fact, Wilson (1979), Cole and Kocherlakota (1998), and Ireland (2003) derive results associating zero nominal interest rates with Pareto-optimal resource allocations in representative-agent models such as Krugman and Svensson's. These optimality results can be rederived for the cashin-advance model developed here in the special case without population growth.

When $n=0$ in the model from above, there is a single representative household that lives from the beginning of period $t=0$ forward. In equilibrium, this household's consumption and hours worked coincide with the per household aggregates, so that by (19) and (25),

$$
h_{t}^{0}=c_{t}^{0}=\left(\frac{1}{1+r_{t}}\right)^{1 /(\gamma-1)}
$$

for all $t=0,1,2, \ldots$ Now consider a social planner, who chooses sequences $\left\{c_{t}^{0}\right.$, $\left.h_{t}^{0}\right\}_{t=0}^{\infty}$ to maximize the representative household's utility

$$
\sum_{t=0}^{\infty} \beta^{t} \ln \left[c_{t}^{0}-(1 / \gamma)\left(h_{t}^{0}\right)^{\gamma}\right]
$$

subject only to the aggregate resource constraints

$$
h_{t}^{0} \geq c_{t}^{0}
$$

for all $t=0,1,2, \ldots$. The solution to this planning problem, which describes the unique symmetric Pareto-optimal allocation, sets

$$
h_{t}^{0}=c_{t}^{0}=1
$$

for all $t=0,1,2, \ldots$.

Comparing (46) and (47) reveals that equilibrium and optimal allocations coincide when monetary policy provides for zero nominal interest rates. Since positive nominal interest rates serve only to distort the representative household's labor supply decisions, zero nominal interest rates are good, not bad. They are more appropriately associated with Friedman's (1969) rule for the optimum quantity of money that with Keynes' (1936) theories of economic depression.

When $n=0$, the representative household can always use its initial stock of real balances to finance the lump-sum taxes required to contract the money supply; this result follows from (45), which shows that in the case without population growth, the value of the stock of real balances exactly offsets the present discounted value 
of the future taxes needed to implement a policy of zero nominal interest rates. When $n>0$, however, some of the taxes associated with monetary contraction must be paid by households from cohorts $s>0$ that are born without an initial endowment of financial assets. And as the money growth rate approaches its lower bound from (43), the tax burden on these households becomes heavier and heavier relative to their ability to pay.

Thus, when the population grows, monetary policies have distributional consequences that potentially make deflation quite costly for many agents. On the other hand, even when $n>0,(19)$ and (25) associate lower nominal interest ratesbrought about through deflation-with higher levels of aggregate consumption, output, and employment. The question becomes: How large are the costs, compared to the benefits?

To answer this question, consider adopting as a welfare criterion for monetary policy the lifetime utility achieved by a representative household that is born into the model's steady state. Woodford (1990) vigorously defends this measure of welfare in models, such as the one used here, in which heterogenous agents are distinguished by their dates of birth. And, in this particular model where there are no predetermined state variables and hence in which there need not be any transitional dynamics en route to the steady state, this welfare criterion corresponds to the lifetime utility enjoyed by all households from all cohorts $s>0$, that is, by all households except those from the initial cohort, which after all constitute a smaller and smaller fraction of the economy's total population as newly born households continue to arrive over the infinite horizon. Weiss (1980), Freeman $(1985,1989,1993)$, and Smith (2002) all present examples of overlapping generations models in which the Friedman rule fails to maximize steady-state utility; Bhattacharya et al. (2004) unify these examples by arguing that in each case, monetary contraction has distributional effects of exactly the same kind that occur in the model with infinitely lived agents studied here. Similarly, Whitesell (1988) finds that steady-state utility is maximized by a positive money growth rate and, indeed, Whitesell's result carries over to the variant of his model developed here.

As an example, suppose that $\beta=0.99$, so that each period in the model can be identified as one quarter year. Let $\gamma=1.6$, the value used by Greenwood et al. (1988) to match estimates of the labor supply elasticity $1 /(\gamma-1)$, and let $n=0.0025$, a small but positive value corresponding to an annualized rate of population growth of about $1 \%$. With these parameter settings, numerical analysis reveals that steady-state utility is maximized when $\sigma=0.0046$, so that the nominal money stock grows at the annualized rate of $1.87 \%$. This optimal policy gives rise to an annualized inflation rate of $0.85 \%$ and an annualized nominal interest rate of $5.02 \%$. The annualized real interest rate of $4.13 \%$ exceeds the annualized rate of time preference of $4.10 \%$, so that as in the additional examples discussed below, each household chooses a growing path for consumption. Aggregate consumption in this preferred steady state is constant at 0.9798 , more than $2 \%$ below the level $c=1$ that, according to (40), is achieved in steady states with zero nominal interest rates. But despite the reduction in aggregate consumption, the representative household prefers this steady state with positive money growth. 
More generally, the welfare effects of different money growth rates can be summarized as follows. Let $U^{0}$ denote the lifetime utility achieved by a representative household that is born into the model's steady state when the money supply is held constant or, equivalently, when the money growth rate equals zero. Next, let $\left\{c_{t}^{s}(\sigma)\right\}_{t=s}^{\infty}$ and $\left\{h_{t}^{s}(\sigma)\right\}_{t=s}^{\infty}$ denote the sequences of consumption and hours worked chosen by this representative household in the alternative steady state in which the money growth rate equals $\sigma$. Finally, let $\omega(\sigma)$ be defined implicitly by

$$
U^{0}=\sum_{t=s}^{\infty} \beta^{t-s} \ln \left\{[1+\omega(\sigma) / 100] c_{t}^{s}(\sigma)-(1 / \gamma)\left[h_{t}^{s}(\sigma)\right]^{\gamma}\right\}
$$

Then $\omega(\sigma)$ measures the permanent percentage increase in consumption that makes the representative household as well off under the money growth rate $\sigma$ as it is under the benchmark of zero money growth; Cooley and Hansen (1989) and Lucas (2000) use similar measures of the welfare costs of inflation.

Table 1 summarizes the effects of changes in the steady-state money growth rate $\sigma$ and reports the value of $\omega(\sigma)$ for various choices of $\sigma$ when, as in the example from above, $\beta=0.99, \gamma=1.6$, and $n=0.0025$. The function $\omega$ takes on negative values for annualized money growth rates as high as $3.65 \%$, indicating that the representative household prefers small but positive values of $\sigma$ to the benchmark setting of $\sigma=0$. The function $\omega$ reaches its minimum at the optimal setting of $\sigma=0.0046$.

As $\sigma$ rises above 0.01 , the negative effects of money growth on aggregate output begin to overwhelm the positive distributional effects, so that $\omega$ turns positive. The largest values of $\omega$, however, occur for negative values of $\sigma$ that make the nominal interest rate equal to zero. A representative household born into the steady state with $\sigma=-0.008$ needs a permanent $5.25 \%$ increase in consumption to be as well off as under a constant money supply. And as the money growth rate approaches -0.01 , the lower bound from (43), the tax burden associated with the zero nominal interest rate becomes so heavy that the household needs almost $60 \%$ more consumption to be as well off as under a constant money supply.

To provide deeper insights into the nature of the distributional effects that make zero nominal interest rates so costly in this model, as well as to confirm Bhattacharya et al.'s intuition that these distributional effects underlie newly born agents preference for positive rates of inflation, Figure 1 displays individual households' patterns of asset accumulation and consumption in four more examples. ${ }^{6}$ Once again, these examples set $\beta=0.99, \gamma=1.6$, and $n=0.0025$ while allowing the money growth rate $\sigma$ to vary. In the first example, illustrated in the figure's two top panels, $\sigma=-0.0099$, very close to the lower bound for money growth allowed by (43). In the second example, $\sigma=-0.0076$, equal to the upper bound in (42). Thus, each of the first two examples features a zero nominal interest rate

\footnotetext{
${ }^{6}$ Note that according to (9), all households from all cohorts work the same number of hours in equilibrium. This result follows from the specification (1) for utility, which as explained earlier implies that there are no wealth effects on labor supply, greatly facilitating the aggregation of quantities chosen by otherwise heterogenous households.
} 
TABLE 1

THE EFFECTS OF STEADY-STATE MONEY GROWTH

\begin{tabular}{|c|c|c|c|c|c|c|}
\hline$\sigma$ & $\pi$ & $r$ & $x$ & $c$ & $m$ & $\omega(\sigma)$ \\
\hline-0.010 & -0.0125 & 0.0000 & 0.0126 & 1.0000 & 37.5000 & 58.7945 \\
\hline-0.009 & -0.0115 & 0.0000 & 0.0116 & 1.0000 & 22.3259 & 23.8144 \\
\hline-0.008 & -0.0105 & 0.0000 & 0.0106 & 1.0000 & 7.1825 & 5.2543 \\
\hline-0.007 & -0.0095 & 0.0006 & 0.0102 & 0.9990 & 1.0060 & 0.0096 \\
\hline-0.006 & -0.0085 & 0.0016 & 0.0102 & 0.9973 & 1.0034 & 0.0077 \\
\hline-0.005 & -0.0075 & 0.0026 & 0.0102 & 0.9957 & 1.0007 & 0.0060 \\
\hline-0.004 & -0.0065 & 0.0036 & 0.0102 & 0.9940 & 0.9980 & 0.0045 \\
\hline-0.003 & -0.0055 & 0.0046 & 0.0102 & 0.9923 & 0.9953 & 0.0031 \\
\hline-0.002 & -0.0045 & 0.0056 & 0.0102 & 0.9907 & 0.9927 & 0.0019 \\
\hline-0.001 & -0.0035 & 0.0066 & 0.0102 & 0.9890 & 0.9900 & 0.0009 \\
\hline 0.000 & -0.0025 & 0.0076 & 0.0102 & 0.9874 & 0.9874 & 0.0000 \\
\hline 0.001 & -0.0015 & 0.0087 & 0.0102 & 0.9857 & 0.9848 & -0.0007 \\
\hline 0.002 & -0.0005 & 0.0097 & 0.0102 & 0.9841 & 0.9821 & -0.0012 \\
\hline 0.003 & 0.0005 & 0.0107 & 0.0102 & 0.9825 & 0.9795 & -0.0016 \\
\hline 0.004 & 0.0015 & 0.0117 & 0.0102 & 0.9808 & 0.9769 & -0.0018 \\
\hline 0.005 & 0.0025 & 0.0127 & 0.0102 & 0.9792 & 0.9743 & -0.0018 \\
\hline 0.006 & 0.0035 & 0.0137 & 0.0102 & 0.9776 & 0.9718 & -0.0017 \\
\hline 0.007 & 0.0045 & 0.0147 & 0.0102 & 0.9760 & 0.9692 & -0.0013 \\
\hline 0.008 & 0.0055 & 0.0157 & 0.0102 & 0.9744 & 0.9666 & -0.0009 \\
\hline 0.009 & 0.0065 & 0.0167 & 0.0102 & 0.9727 & 0.9641 & -0.0002 \\
\hline 0.010 & 0.0075 & 0.0177 & 0.0102 & 0.9711 & 0.9615 & 0.0006 \\
\hline 0.020 & 0.0175 & 0.0278 & 0.0102 & 0.9553 & 0.9366 & 0.0176 \\
\hline 0.030 & 0.0274 & 0.0379 & 0.0102 & 0.9399 & 0.9125 & 0.0506 \\
\hline 0.040 & 0.0374 & 0.0479 & 0.0102 & 0.9249 & 0.8893 & 0.0994 \\
\hline 0.050 & 0.0474 & 0.0580 & 0.0102 & 0.9103 & 0.8669 & 0.1635 \\
\hline 0.100 & 0.0973 & 0.1084 & 0.0102 & 0.8424 & 0.7658 & 0.7031 \\
\hline 0.150 & 0.1471 & 0.1588 & 0.0101 & 0.7822 & 0.6802 & 1.5812 \\
\hline 0.200 & 0.1970 & 0.2092 & 0.0101 & 0.7287 & 0.6072 & 2.7662 \\
\hline
\end{tabular}

Notes: All examples set $\gamma=1.6, \beta=0.99$, and $n=0.0025$. Figures listed for $\sigma=-0.010$ are the limits as $\sigma$ approaches -0.010 from above. $\sigma=$ money growth rate, $\pi=$ inflation rate, $r=$ nominal interest rate, $x=$ real interest rate, $c=$ consumption, $m=$ real money balances, $\omega(\sigma)=$ permanent percentage increase in consumption required to make the representative household as well off as under zero money growth.

but, as can be seen from the graphs themselves, very different patterns for individual asset holdings and consumptions. The remaining two examples increase the rate of money growth still further, to 0.01 and then to 0.10 ; both of these cases feature positive nominal interest rates. The dotted line in each panel traces out quantities for the representative household from the initial cohort $s=0$, whereas the solid line traces out paths for households from all other cohorts $s>0$ that, by assumption, are born without financial assets.

The same costs and benefits of deflationary policies discussed above manifest themselves clearly in Figure 1. As the money growth rate rises, the distortionary effects of positive nominal interest rates reduce aggregate consumption. At the same time, however, an increase in the rate of money growth reallocates wealth 
$\sigma=-\mathbf{0 . 0 0 9 9}$

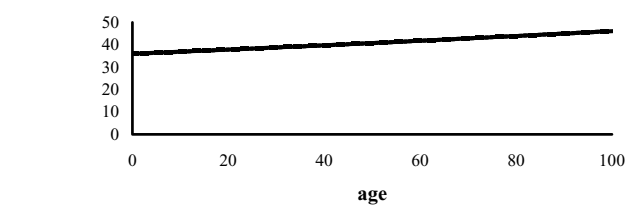

$\sigma=-0.0076$

assets

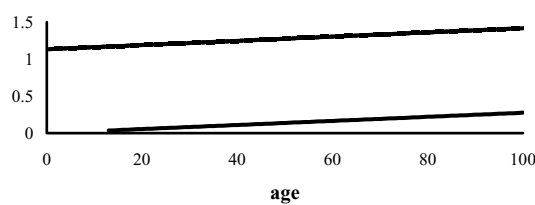

$\sigma=\mathbf{0 . 0 1 0 0}$

assets

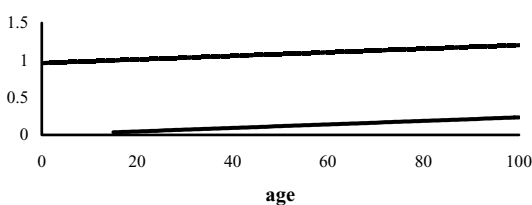

$\sigma=0.1000$

assets

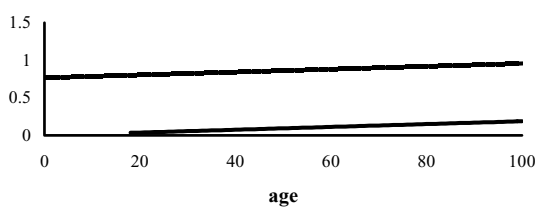

consumption

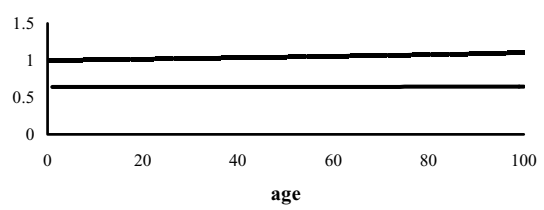

consumption

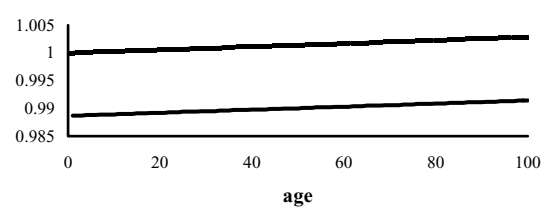

consumption

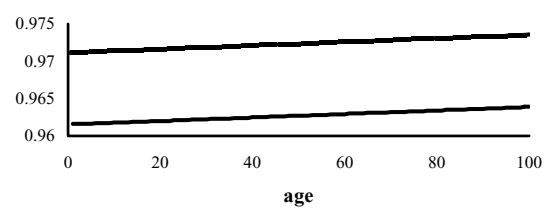

consumption

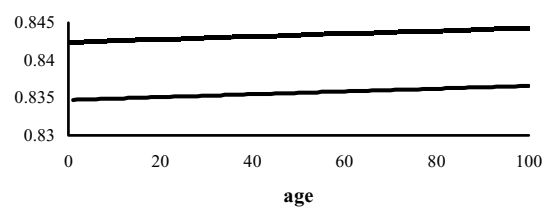

Notes: Dotted line traces out values for a representative household from the initial cohort. Solid line traces out values for representative households from each subsequent cohort. All examples set $\beta=0.99, y=1.6$, and $n=0.0025$.

FIGURE 1

INDIVIDUAL HOUSEHOLDS' ASSETS AND CONSUMPTION IN STEADY STATES WITH CONSTANT MONEY GROWTH VIA EQUAL LUMP-SUM TRANSFERS

away from households from the initial cohort $s=0$ to households from subsequent cohorts $s>0$.

Thus, in one way, the introduction of the real balance effect into an otherwise conventional cash-in-advance model works exactly as promised by Pigou, Patinkin, and others: It eliminates the liquidity trap, giving the central bank control over the price level even when the nominal interest rate hits its lower bound of zero. Yet here, the same distributional effects that allow the real balance effect to operate also make zero nominal interest rates quite costly for some agents. Paradoxically, a zero nominal interest rate is something to be achieved in the conventional model, where the liquidity trap survives. With the introduction of 
the real balance effect, a zero nominal interest rate becomes something to be avoided.

\section{REHABILITATING THE FRIEDMAN RULE}

Bhattacharya et al. (2004) also highlight the key role played by distributional effects in more conventional overlapping generations models by constructing more elaborate policy regimes that provide additional fiscal transfers to individual agents who might otherwise be harmed by monetary contractions. Bhattacharya et al. show, in particular, that once the distributional effects of deflation are neutralized by the appropriate set of fiscal transfers, the Friedman rule once again becomes part of an optimal policy mix. These results generalize earlier examples presented by Abel (1987) and Gahvari (1988), in which the Friedman rule becomes optimal in an overlapping generations context, but only when coupled with a complementary fiscal policy that offsets the distributional consequences.

Here, again, the same results apply. Once the distributional effects of monetary contraction are neutralized by additional fiscal transfers, the general model with population growth behaves exactly like the special case with $n=0$ : The real balance effect disappears, the liquidity trap reemerges, and the Friedman rule helps support Pareto-optimal resource allocations once again.

To fill in the details, suppose as above that the government issues no bonds and acts to increase the total nominal money supply at the constant rate $\sigma$, so that (19)-(21) continue to depict the aggregate market-clearing conditions for goods, labor, bonds, and money. Suppose now, however, that in addition to making a common lump-sum transfer of real value $\bar{\tau}$ to each household alive during each period $t=0,1,2, \ldots$, the government also makes a special lump-sum of real value $\bar{m}$ to each newly born household at the beginning of each period $t=1,2,3, \ldots$, in an attempt to put those households on a more equal footing with older households that have already accumulated stocks of financial assets.

Under monetary-fiscal policy combinations of this type, the definitions of $\tau_{t}$ and $\tau_{u, t}$ imply that

$$
\tau_{t}=\tau_{t, t}=\bar{\tau}+\left(\frac{n}{1+n}\right) \bar{m}
$$

for all $t=0,1,2, \ldots$, whereas

$$
\tau_{u, t}=\bar{\tau}
$$

for all $t=0,1,2, \ldots$, and $u=t+1, t+2, t+3, \ldots$, since only the newborns receive the additional transfer $\bar{m}$. The government, of course, cannot choose the three settings for $\sigma, \bar{\tau}$, and $\bar{m}$ independently: (21) and (48) imply that these values must satisfy

$$
\bar{\tau}+\left(\frac{n}{1+n}\right) \bar{m}=\sigma m
$$

in any steady-state equilibrium in which aggregate per household real balances $m_{t}$ are constant and equal to $m$. 
In such a steady state, $m_{t}=m$ measures aggregate per household real balances held at the beginning of each period $t=0,1,2, \ldots$, before the government makes any transfers to households alive during that period. And, by assumption, newly born households start their lives without money. Taken together, these observations imply that at the beginning of each period, households born during previous periods hold, on average, money balances of real value $(1+n) m$. Hence, the government can put newly born households on exactly the same footing as older households by setting $\bar{m}=(1+n) m$; it can then ensure that the total money supply grows at the constant $\sigma$ by setting $\bar{\tau}=(\sigma-n) m$. Under this monetaryfiscal policy regime, therefore, the government taxes older households in order to provide transfers to newly born households; these transfers help neutralize the distributional effects that simpler policies of money growth or contraction would otherwise have.

Under this monetary-fiscal policy regime, (7) and (14)-(18) once again imply that $x_{t}=x, r_{t}=r, \pi_{t+1}=\pi, m_{t}=m$, and $c_{t}=c$ for all $t=0,1,2, \ldots$, in any steady-state equilibrium. Now, however, these steady-state values must satisfy

$$
\begin{gathered}
1+x=(1+r) /(1+\pi) \\
1+\pi=(1+\sigma) /(1+n) \\
c=\left(\frac{1}{1+r}\right)^{1 /(\gamma-1)} \\
(1+\sigma) m \geq c, \quad r \geq 0, \quad r[(1+\sigma) m-c]=0
\end{gathered}
$$

and

$$
\begin{aligned}
c= & \frac{1}{\gamma}\left(\frac{1}{1+r}\right)^{\gamma /(\gamma-1)} \\
& +(1-\beta)\left\{\left[1-\frac{n}{x}+\left(\frac{1+x}{x}\right) \sigma\right] m+\left(\frac{\gamma-1}{\gamma}\right)\left(\frac{1+x}{x}\right)\left(\frac{1}{1+r}\right)^{\gamma /(\gamma-1)}\right\}
\end{aligned}
$$

Equations (49)-(52), describing steady-state equilibria under this modified monetary-fiscal policy regime, coincide exactly with (29)-(32), describing steady states under policies of constant money growth without the additional fiscal transfers. The consumption function (53) for the case with fiscal transfers differs from (33) for the case without, however, suggesting that there may be important differences in consumption patterns across these two types of policy regimes.

Suppose, finally, that the government sets $\sigma=\beta(1+n)-1$ : This choice adjusts the money growth rate associated with the Friedman rule in (34) to account for the possibility of a positive rate of population growth. Part A.5 of the appendix shows 
that with this setting for $\sigma$, the steady-state values of $r, \pi, x$, and $c$ are uniquely determined as

$$
\begin{gathered}
r=0 \\
1+\pi=\beta \\
1+x=1 / \beta
\end{gathered}
$$

and

$$
c=1
$$

whereas the steady-state value of $m$ need only satisfy

$$
(1+n) m \geq \beta
$$

Part A.5 of the appendix also shows that with this setting for $\sigma$, individual households from all cohorts $s=0,1,2, \ldots$ choose

$$
c_{t}^{s}=h_{t}^{s}=1
$$

for all $t=s, s+1, s+2, \ldots$.

Thus, when fiscal transfers undo the distributional effects that would otherwise result from this policy of monetary contraction, the economy with population growth behaves like one with a single representative agent. In (54) and (55), the nominal interest rate reaches its lower bound of zero as the rate of deflation coincides with the rate of time preference; in (56), meanwhile, the real interest rate is pinned down by the rate of time preference, exactly as in the standard Sidrauski (1967) model. Equation (58) confirms that without distributional effects, the real balance effect vanishes, allowing Krugman (1998) and Svensson's (1999) liquidity trap to reemerge, as the steady-state level of real balances is no longer uniquely determined. Nevertheless, outcomes in this equilibrium with zero nominal interest rates are good, not bad: (57) and (59) reveal that when complemented by the appropriate fiscal transfer scheme, the Friedman rule again supports the unique symmetric Pareto-optimal allocation. Steady-state utility under this monetaryfiscal policy regime is higher than under any of the policies of constant money growth via equal-lump sum transfers.

"Le bon dieu est dans le détail," or so said Gustave Flaubert. More recently, others have paraphrased: "the Devil is in the details."7 Either way—good God or Devil-the proverb applies here. Zero nominal interest rates can be very good or very bad: Which one depends critically on the details of how the policy is actually implemented.

\footnotetext{
${ }^{7}$ See Titelman (1996, p.119) for a brief discussion.
} 
A.1. Deriving the Infinite-Horizon Budget Constraint. To derive the infinitehorizon budget constraint (6), multiply the single-period budget constraint (3) by $Q_{t}$ and rearrange to obtain

$Q_{t}\left(M_{t}^{s}+B_{t}^{s}\right)+Q_{t}\left(T_{t}^{s}+P_{t} h_{t}^{s}\right) \geq Q_{t} P_{t} c_{t}^{s}+\left(Q_{t}-Q_{t+1}\right) M_{t+1}^{s}+Q_{t+1}\left(M_{t+1}^{s}+B_{t+1}^{s}\right)$

Sum from $t$ through $T \geq t$ to obtain

$$
\begin{aligned}
Q_{t}\left(M_{t}^{s}+B_{t}^{s}\right)+\sum_{u=t}^{T} Q_{u}\left(T_{u}^{s}+P_{t} h_{t}^{s}\right) \geq & \sum_{u=t}^{T} Q_{u}\left[P_{u} c_{u}^{s}+\left(\frac{r_{u}}{1+r_{u}}\right) M_{u+1}^{s}\right] \\
& +Q_{T+1}\left(M_{T+1}^{s}+B_{T+1}^{s}\right)
\end{aligned}
$$

Now use the no-Ponzi-scheme constraint (5) at $t=T$ to obtain

$$
Q_{t}\left(M_{t}^{s}+B_{t}^{s}\right)+\sum_{u=t}^{\infty} Q_{u}\left(T_{u}^{s}+P_{t} h_{t}^{s}\right) \geq \sum_{u=t}^{T} Q_{u}\left[P_{u} c_{u}^{s}+\left(\frac{r_{u}}{1+r_{u}}\right) M_{u+1}^{s}\right]
$$

Finally, take the limit as $T \rightarrow \infty$ to arrive at (6).

A.2. Solving the Household's Problem. Let $\lambda_{t}^{s}$ and $\mu_{t}^{s}$ denote the nonnegative Lagrange multipliers on the household's budget and cash-in-advance constraints for period $t$. Since the household's utility function is increasing and concave, necessary conditions for optimality include the usual first-order and complementary slackness conditions, which are given by

$$
\frac{1}{c_{t}^{s}-(1 / \gamma)\left(h_{t}^{s}\right)^{\gamma}}=\lambda_{t}^{s}+\mu_{t}^{s}
$$

$$
\frac{\left(h_{t}^{s}\right)^{\gamma-1}}{c_{t}^{s}-(1 / \gamma)\left(h_{t}^{s}\right)^{\gamma}}=\lambda_{t}^{s}
$$

$$
\frac{\lambda_{t}^{s}}{P_{t}}=\frac{\beta\left(\lambda_{t+1}^{s}+\mu_{t+1}^{s}\right)}{P_{t+1}}
$$

$$
\frac{\lambda_{t}^{s}+\mu_{t}^{s}}{\left(1+r_{t}\right) P_{t}}=\frac{\beta\left(\lambda_{t+1}^{s}+\mu_{t+1}^{s}\right)}{P_{t+1}}
$$

$$
\frac{M_{t}^{s}+T_{t}^{s}+B_{t}^{s}}{P_{t}}+h_{t}^{s}=c_{t}^{s}+\frac{B_{t+1}^{s}}{\left(1+r_{t}\right) P_{t}}+\frac{M_{t+1}^{s}}{P_{t}}
$$

$$
\frac{M_{t}^{s}+T_{t}^{s}+B_{t}^{s}}{P_{t}}-\frac{B_{t+1}^{s}}{\left(1+r_{t}\right) P_{t}} \geq c_{t}^{s}
$$




$$
\mu_{t}^{s} \geq 0
$$

and

$$
\mu_{t}^{s}\left[\frac{M_{t}^{s}+T_{t}^{s}+B_{t}^{s}}{P_{t}}-\frac{B_{t+1}^{s}}{\left(1+r_{t}\right) P_{t}}-c_{t}^{s}\right]=0
$$

for all $t=s, s+1, s+2, \ldots$.

Necessary conditions also include the transversality condition

$$
\lim _{t \rightarrow \infty} Q_{t+1} W_{t+1}=\lim _{t \rightarrow \infty} Q_{t+1}\left(M_{t+1}^{s}+B_{t+1}^{s}\right)=0
$$

To derive (A.7), note first that since the net nominal interest rate must always be nonnegative, the sequence $\left\{Q_{t}\right\}_{t=0}^{\infty}$ is nonincreasing, with

$$
Q_{t}=\left(1+r_{t}\right) Q_{t+1} \geq Q_{t+1}
$$

for all $t=0,1,2, \ldots$ Note, too, that $\left\{Q_{t+1} W_{t+1}^{s}\right\}_{t=s}^{\infty}$ is also nonincreasing, since for any $t=s+1, s+2, s+3, \ldots$, the definition of $W_{t+1}^{s}$, the period $t$ budget constraint, the fact that $Q_{t} \geq Q_{t+1}$, and the nonnegativity constraints from (4) imply

$$
\begin{aligned}
Q_{t+1} W_{t+1}^{s}-Q_{t} W_{t}^{s} & =Q_{t+1}\left(M_{t+1}^{s}+B_{t+1}^{s}\right)-Q_{t}\left(M_{t}^{s}+B_{t}^{s}\right)-Q_{t}\left(T_{t}^{s}+P_{t} h_{t}^{s}\right) \\
& \leq\left(Q_{t+1}-Q_{t}\right) M_{t+1}^{s}-Q_{t} P_{t} c_{t}^{s} \\
& \leq 0
\end{aligned}
$$

Next, note that if $\left\{c_{t}^{s}, h_{t}^{s}, M_{t+1}^{s}, B_{t+1}^{s}\right\}_{t=s}^{\infty}$ are optimal choices for the representative household of cohort $s$, the implied sequence $\left\{Q_{t+1} W_{t+1}^{s}\right\}_{t=s}^{\infty}$ must satisfy

$$
\inf _{t \geq s} Q_{t+1} W_{t+1}^{s}=0
$$

To see this, suppose to the contrary that there exists an $\varepsilon>0$ such that $Q_{t+1} W_{t+1}^{s} \geq$ $\varepsilon$ for all $t=s, s+1, s+2, \ldots$, and construct new sequences $\left\{\tilde{c}_{t}^{s}, \tilde{h}_{t}^{s}, \tilde{M}_{t+1}^{s}, \tilde{B}_{t+1}^{s}\right\}_{t=s}^{\infty}$ as

$$
\begin{gathered}
\tilde{c}_{s}^{s}=c_{s}^{s}+\frac{\varepsilon}{Q_{s} P_{s}}, \tilde{c}_{t}^{s}=c_{t}^{s} \quad \text { for } t=s+1, s+2, s+3, \ldots \\
\tilde{h}_{t}^{s}=h_{t}^{s} \quad \text { for } t=s, s+1, s+2, \ldots \\
\tilde{M}_{t+1}^{s}=M_{t+1}^{s} \quad \text { for } t=s, s+1, s+2, \ldots \\
\tilde{B}_{t+1}^{s}=B_{t+1}^{s}-\frac{\varepsilon}{Q_{t+1}} \quad \text { for } t=s, s+1, s+2, \ldots
\end{gathered}
$$


These new sequences satisfy all of the household's constraints: (2)-(5) for all $t=s, s+1, s+2, \ldots$ Moreover, they provide the household with a higher level of utility than the original sequences. But this contradicts the assumption that the original sequences are optimal. Hence $\inf _{t \geq s} Q_{t+1} W_{t+1}^{s}=0$ must hold.

Together $\left\{Q_{t+1} W_{t+1}^{s}\right\}_{t=s}^{\infty}$ are nonincreasing and $\inf _{t \geq s} Q_{t+1} W_{t+1}^{s}=0$ imply that (A.7) must hold at the optimum. This establishes that (A.1)-(A.7) are necessary conditions for optimality.

To prove that (A.1)-(A.7) are also sufficient conditions for optimality, suppose that $\left\{c_{t}^{s}, h_{t}^{s}, M_{t+1}^{s}, B_{t+1}^{s}\right\}_{t=s}^{\infty}$ satisfy (A.1)-(A.7), but that alternative sequences $\left\{\hat{c}_{t}^{s}, \hat{h}_{t}^{s}, \hat{M}_{t+1}^{s}, \hat{B}_{t+1}^{s}\right\}_{t=s}^{\infty}$ satisfy (2)-(5) for all $t=s, s+1, s+2, \ldots$, and provide the household with a higher level of utility. Then

$$
\begin{aligned}
0< & \lim _{T \rightarrow \infty} \sum_{t=s}^{T} \beta^{t-s}\left\{\ln \left[\hat{c}_{t}^{s}-(1 / \gamma)\left(\hat{h}_{t}^{s}\right)^{\gamma}\right]-\ln \left[c_{t}^{s}-(1 / \gamma)\left(h_{t}^{s}\right)^{\gamma}\right]\right\} \\
< & \lim _{T \rightarrow \infty} \sum_{t=s}^{T} \beta^{t-s}\left\{\left[\frac{1}{c_{t}^{s}-(1 / \gamma)\left(h_{t}^{s}\right)^{\gamma}}\right]\left(\hat{c}_{t}^{s}-c_{t}^{s}\right)-\left[\frac{\left(h_{t}^{s}\right)^{\gamma-1}}{c_{t}^{s}-(1 / \gamma)\left(h_{t}^{s}\right)^{\gamma}}\right]\left(\hat{h}_{t}^{s}-h_{t}^{s}\right)\right\} \\
= & \lim _{T \rightarrow \infty} \sum_{t=s}^{T} \beta^{t-s}\left[\lambda_{t}^{s}\left(\hat{c}_{t}^{s}-c_{t}^{s}\right)-\lambda_{t}^{s}\left(\hat{h}_{t}^{s}-h_{t}^{s}\right)+\mu_{t}^{s}\left(\hat{c}_{t}^{s}-c_{t}^{s}\right)\right] \\
\leq & \lim _{T \rightarrow \infty} \sum_{t=s}^{T} \beta^{t-s} \lambda_{t}^{s}\left[\frac{\hat{M}_{t}^{s}-M_{t}^{s}}{P_{t}}+\frac{\hat{B}_{t}^{s}-B_{t}^{s}}{P_{t}}-\frac{\hat{M}_{t+1}^{s}-M_{t+1}^{s}}{P_{t}}-\frac{\hat{B}_{t+1}^{s}-B_{t+1}^{s}}{\left(1+r_{t}\right) P_{t}}\right] \\
& +\lim _{T \rightarrow \infty} \sum_{t=s}^{T} \beta^{t-s} \mu_{t}^{s}\left[\frac{\hat{M}_{t}^{s}-M_{t}^{s}}{P_{t}}+\frac{\hat{B}_{t}^{s}-B_{t}^{s}}{P_{t}}-\frac{\hat{B}_{t+1}^{s}-B_{t+1}^{s}}{\left(1+r_{t}\right) P_{t}}\right] \\
= & \lim _{T \rightarrow \infty} \frac{\beta^{T-s} \lambda_{T}^{s}\left(M_{T+1}^{s}-\hat{M}_{T+1}^{s}\right)}{P_{T}}+\frac{\beta^{T-s}\left(\lambda_{T}^{s}+\mu_{T}^{s}\right)\left(B_{T+1}^{s}-\hat{B}_{T+1}^{s}\right)}{\left(1+r_{T}\right) P_{T}} \\
= & \left(\frac{\lambda_{t}^{s}+\mu_{t}^{s}}{Q_{s} P_{s}}\right) \lim _{T \rightarrow \infty}\left[Q_{T+1}\left(M_{T+1}^{s}+B_{T+1}^{s}\right)-Q_{T+1}\left(\hat{M}_{T+1}^{s}+\hat{B}_{T+1}^{s}\right)\right] \\
= & -\left(\frac{\lambda_{t}^{s}+\mu_{t}^{s}}{Q_{s} P_{s}}\right) \lim _{T \rightarrow \infty} Q_{T+1}\left(\hat{M}_{T+1}^{s}+\hat{B}_{T+1}^{s}\right) \\
\leq & 0
\end{aligned}
$$

by the concavity of the utility function, by (A.1) and (A.2), by (2), (3), (A.5), and (A.6c), by (A.3) and (A.4), by (A.3) and (A.4) again, by (A.7), and by (5). But all of this contradicts the assumption that $\left\{\hat{c}_{t}^{s}, \hat{h}_{t}^{s}, \hat{M}_{t+1}^{s}, \hat{B}_{t+1}^{s}\right\}_{t=s}^{\infty}$ provide the household with higher utility than $\left\{c_{t}^{s}, h_{t}^{s}, M_{t+1}^{s}, B_{t+1}^{s}\right\}_{t=s}^{\infty}$. Hence, (A.1)-(A.7) are both necessary and sufficient for a solution to the household's problem.

Now let $m_{t}^{s}, b_{t}^{s}, \tau_{t}^{s}, \pi_{t}, x_{t}$, and $a_{t}^{s}$ be as defined in the text. Substitute (A.4) into (A.3) to obtain

$$
\mu_{t}^{s}=r_{t} \lambda_{t}^{s}
$$


and combine this result with (A.1) and (A.2) to arrive at (9) from the text. Use (A.5) and (A.8) to rewrite (A.6a)-(A.6c) as (10) from the text.

Next, consider (A.4), which can be rewritten using (7) and (A.1) as

$$
c_{t+1}^{s}-(1 / \gamma)\left(h_{t+1}^{s}\right)^{\gamma}=\beta\left(1+x_{t}\right)\left[c_{t}^{s}-(1 / \gamma)\left(h_{t}^{s}\right)^{\gamma}\right]
$$

the Euler equation linking the household's intertemporal marginal rate of substitution to the real interest rate. Multiply (A.5) by $P_{t} Q_{t}$ and, as above, sum from $t$ through $T \geq t$ and take the limit as $T \rightarrow \infty$ to obtain

$$
Q_{t}\left(M_{t}^{s}+B_{t}^{s}\right)+\sum_{u=t}^{\infty} Q_{u}\left(T_{u}^{s}+P_{t} h_{t}^{s}\right)=\sum_{u=t}^{\infty} Q_{u}\left[P_{u} c_{u}^{s}+\left(\frac{r_{u}}{1+r_{u}}\right) M_{u+1}^{s}\right]
$$

which is just (6) with equality. Since

$$
\frac{Q_{u}}{Q_{t} P_{t}}=\left[\prod_{v=t}^{u-1}\left(\frac{1}{1+x_{v}}\right)\right] \frac{1}{P_{u}}
$$

(A.10) can be rewritten as

$$
\begin{aligned}
a_{t}^{s}+\sum_{u=t}^{\infty}\left[\prod_{v=t}^{u-1}\left(\frac{1}{1+x_{v}}\right)\right]\left(\tau_{u}^{s}+h_{u}^{s}\right)= & \sum_{u=t}^{\infty}\left[\prod_{v=t}^{u-1}\left(\frac{1}{1+x_{v}}\right)\right] \\
& \times\left[c_{u}^{s}+\frac{r_{u}\left(1+\pi_{u+1}\right) m_{u+1}^{s}}{1+r_{u}}\right]
\end{aligned}
$$

Substitute (9), (10), and (A.9) into (A.11) to obtain (11) from the text.

Use (7) and (8) to recast (A.5) in real terms as

$$
a_{t}^{s}+\tau_{t}^{s}+h_{t}^{s}=c_{t}^{s}+\left(\frac{1}{1+x_{t}}\right)\left(a_{t+1}^{s}+r_{t} m_{t+1}^{s}\right)
$$

then use (9) and (10) to rewrite (A.12) as (12) from the text. Finally, use

$$
\frac{Q_{t+1}}{Q_{s} P_{s}}=\left[\prod_{v=s}^{t}\left(\frac{1}{1+x_{v}}\right)\right] \frac{1}{P_{t+1}}
$$

and (8) to replace (A.7) with (13) from the text.

A.3. Deriving the Steady-State Conditions. Equations (24)-(28) describe the equilibrium behavior of the five aggregate variables $x_{t}, r_{t}, \pi_{t+1}, m_{t}$, and $c_{t}$ under policies of constant money growth via equal lump-sum monetary transfers; in a steady-state equilibrium, $x_{t}=x, r_{t}=r, \pi_{t+1}=\pi, m_{t}=m$, and $c_{t}=c$ for all $t=0$, 
$1,2, \ldots$ Equations (24), (25), and (27) immediately imply that these steady-state values must satisfy (29), (31), (33).

In a steady state, $(28)$ becomes

$$
m=\left(\frac{1+x}{1+n}\right)\left[(1+\sigma) m-\left(\frac{1}{1+r}\right) r c\right]
$$

or, using (26),

$$
m=\left(\frac{1+x}{1+n}\right)\left[(1+\sigma) m-\left(\frac{1}{1+r}\right) r(1+n)(1+\pi) m\right]
$$

Divide both sides of this last equality by $m$ and rearrange using (29) to obtain (30); (30) then allows (26) to be rewritten as (32).

A.4. Deriving the Lower Bound on Money Growth. In light of the Euler Equation (A.9), $c_{t}^{s}-(1 / \gamma)\left(h_{t}^{s}\right)^{\gamma}>0$ for all $t=s, s+1, s+2, \ldots$, as required by (4), if and only if $c_{s}^{s}-(1 / \gamma)\left(h_{s}^{s}\right)^{\gamma}>0$. Combining (9), (11), and (21) with the initial condition $a_{s}^{s}=0$, which applies to any household born into a steady state with $n>0$, reveals that

$$
c_{s}^{s}-(1 / \gamma)\left(h_{s}^{s}\right)^{\gamma}=(1-\beta)\left(\frac{1+x}{x}\right)\left[\sigma m+\left(\frac{\gamma-1}{\gamma}\right)\left(\frac{1}{1+r}\right)^{\gamma /(\gamma-1)}\right]
$$

in any steady state with $n>0$. Equivalently, using (33),

$$
c_{s}^{s}-(1 / \gamma)\left(h_{s}^{s}\right)^{\gamma}=c-\frac{1}{\gamma}\left(\frac{1}{1+r}\right)^{\gamma /(\gamma-1)}-(1-\beta) m
$$

When $r=0,(40)$ and (41) imply that the right-hand side of this last equality is strictly positive if and only if the money growth rate satisfies (43).

A.5. Characterizing the Steady State under the Friedman Rule with Fiscal Transfers. Equations (49)-(53) determine the steady-state values $x, r, \pi, m$, and $c$ under the monetary-fiscal policy regime described in the text. When, under this regime, the money growth rate $\sigma$ is set equal to $\beta(1+n)-1,(49)$ and (50) imply

$$
1+x=(1+r) / \beta
$$

and

$$
1+\pi=\beta
$$


Substituting (51), (A.13), and (A.14) into (53) yields

$$
\begin{aligned}
\left(\frac{1}{1+r}\right)^{1 /(\gamma-1)}= & \frac{1}{\gamma}\left(\frac{1}{1+r}\right)^{\gamma /(\gamma-1)} \\
& +\left(\frac{1-\beta}{1+r-\beta}\right)\left[r(1+\sigma) m+\left(\frac{\gamma-1}{\gamma}\right)\left(\frac{1}{1+r}\right)^{1 /(\gamma-1)}\right]
\end{aligned}
$$

In light of (52), however, this last expression collapses to

$$
\gamma(1+r)^{2}-(1+\gamma)(1+r)+1=0
$$

Equation (A.15) admits two possible solutions for $r, r=0$ and $r=(1-\gamma) / \gamma$, but only the first of these is nonnegative as required by (52). It therefore follows immediately from (51) and (A.13)-(A.15) that the steady-state values of $r, \pi, x$, and $c$ are uniquely determined as shown in (54)-(57), whereas (52) requires only that $m$ satisfy (58) from the text.

Equations (11) and (12), meanwhile, characterize each individual household's pattern of consumption and asset holdings under arbitrary government policies. In the steady state just described, however, (54) and (56) must hold, as must the expressions $a_{s}^{s}+\tau_{s}^{s}=(1+\sigma) m=\beta(1+n) m$ and $\tau_{t}^{s}=\bar{\tau}=(\sigma-n) m=$ $(\beta-1)(1+n) m$ for all $t=s+1, s+2, s+3, \ldots$, called for by the design of policy regime. Hence, for all $s=0,1,2, \ldots$, these equations specialize to

$$
c_{t}^{s}=1
$$

and

$$
a_{t+1}^{s}=(1+n) m
$$

for all $t=s, s+1, s+2, \ldots$. The first of these two expressions, together with (9) and (54), then implies that (59) must hold.

\section{REFERENCES}

Abel, A. B., "Optimal Monetary Growth," Journal of Monetary Economics 19 (1987), $437-50$

Barro, R. J., "Are Government Bonds Net Wealth?" Journal of Political Economy 82 (1974), 1095-117.

Bhattacharya, J., J. H. Haslag, and S. Russell, "The Role of Money in Two Alternative Models: When Is the Friedman Rule Optimal, and Why?" Manuscript, University of Missouri, 2004.

Blanchard, O. J., "Debt, Deficits, and Finite Horizons," Journal of Political Economy 93 (1985), 223-47.

Buiter, W. H., "Death, Birth, Productivity Growth and Debt Neutrality," Economic Journal 98 (1988), 279-93.

CoHEN, D., "Inflation, Wealth and Interest Rates in an Intertemporal Optimizing Model," Journal of Monetary Economics 16 (1985), 73-85. 
Cole, H. L., And N. Kocherlakota, "Zero Nominal Interest Rates: Why They're Good and How to Get Them," Federal Reserve Bank of Minneapolis Quarterly Review 22 (1998), 2-10.

Cooley, T. F., And G. D. Hansen, "The Inflation Tax in a Real Business Cycle Model," American Economic Review 79 (1989), 733-48.

DE Scitovszky, T., "Capital Accumulation, Employment and Price Rigidity," Review of Economic Studies 8 (1941), 69-88.

Freeman, S., "Transactions Costs and the Optimal Quantity of Money," Journal of Political Economy 93 (1985), 146-57.

__ " "Fiat Money as a Medium of Exchange," International Economic Review 30 (1989), $137-51$.

_- "Resolving Differences over the Optimal Quantity of Money," Journal of Money, Credit, and Banking 25 (1993), 801-11.

Friedman, M., "The Optimum Quantity of Money," in The Optimum Quantity of Money and Other Essays (Chicago: Aldine Publishing Company, 1969), 1-50.

Gahvari, F., "Lump-Sum Taxation and the Superneutrality and Optimum Quantity of Money in Life Cycle Growth Models," Journal of Public Economics 36 (1988), 33967.

Greenwood, J., Z. Hercowitz, and G.W. Huffman, "Investment, Capacity Utilization, and the Real Business Cycle." American Economic Review 78 (1988), 402-17.

- R. Rogerson, and R. Wright, "Household Production in Real Business Cycle Theory," in T. F. Cooley, ed., Frontiers of Business Cycle Research (Princeton: Princeton University Press, 1995), 157-74.

Haberler, G., Prosperity and Depression: A Theoretical Analysis of Cyclical Movements, 3rd edition (New York: United Nations, 1946).

Hicks, J. R., "Mr. Keynes and the 'Classics'; A Suggested Interpretation," Econometrica 5 (1937), 147-59.

Ireland, P. N., "Implementing the Friedman Rule," Review of Economic Dynamics 6 (2003), 120-34.

Keynes, J. M., The General Theory of Employment, Interest, and Money (New York: Harcourt, Brace and Company, 1936).

Krugman, P. R., "It's Baaack: Japan's Slump and the Return of the Liquidity Trap," Brookings Papers on Economic Activity (1998), 137-87.

LuCAs, R. E., JR., "Equilibrium in a Pure Currency Economy,” Economic Inquiry 18 (1980), 203-20.

__ "Inflation and Welfare," Econometrica 68 (2000), 247-74.

McCallum, B. T., "Some Issues Concerning Interest Rate Pegging, Price Level Determinacy, and the Real Bill Doctrine," Journal of Monetary Economics 17 (1986), 135-60.

Mussa, M., "Summary Panel: Reflections on Monetary Policy at Low Inflation," Journal of Money, Credit, and Banking 32 (2000), 1100-6.

Patinkin, D., Money, Interest, and Prices, 2nd edition (New York: Harper and Row, 1965).

Pigou, A. C., "The Classical Stationary State," Economic Journal 53 (1943), 343-51.

SACHS, J., "Energy and Growth under Flexible Exchange Rates: A Simulation Study," in J. S. Bhandari and B. H. Putnam with J. H. Levin, eds., Economic Interdependence and Flexible Exchange Rates (Cambridge, MA: MIT Press, 1983), 191-220.

Sidrauski, M., "Rational Choice and Patterns of Growth in a Monetary Economy," American Economic Review 57 (1967), 534-44.

Smith, B. D., "Monetary Policy, Banking Crises, and the Friedman Rule," American Economic Review 92 (2002), 128-34.

Svensson, L. E. O., "How Should Monetary Policy Be Conducted in an Era of Price Stability?" in New Challenges for Monetary Policy (Kansas City: Federal Reserve Bank of Kansas City, 1999), 195-259.

Titelman, G., The Random House Dictionary of Popular Proverbs and Sayings (New York: Random House, 1996).

Tobin, J., "Money and Economic Growth,” Econometrica 33 (1965), 671-84. 
WeIL, P., "Is Money Net Wealth?” International Economic Review 32 (1991), 37-53.

WeIss, L., "The Effects of Money Supply on Economic Welfare in the Steady State," Econometrica 48 (1980), 565-76.

Whitesell, W. C., "Age Heterogeneity and the Tobin Effect with Infinite Horizons," Finance and Economics Discussion Series 4, Division of Research and Statistics, Federal Reserve Board, 1988.

WILSON, C., "An Infinite Horizon Model with Money," in J. R. Green and J. A. Scheinkman, eds., General Equilibrium, Growth, and Trade: Essays in Honor of Lionel McKenzie (New York: Academic Press, 1979), 79-104.

Woodford, M., "The Optimum Quantity of Money," in B. M. Friedman and F. H. Hahn, eds., Handbook of Monetary Economics (Amsterdam: Elsevier, 1990), 1067-152. , "Monetary Policy and Price-Level Determinacy in a Cash-in-Advance Economy," Economic Theory 4 (1994), 345-80. 